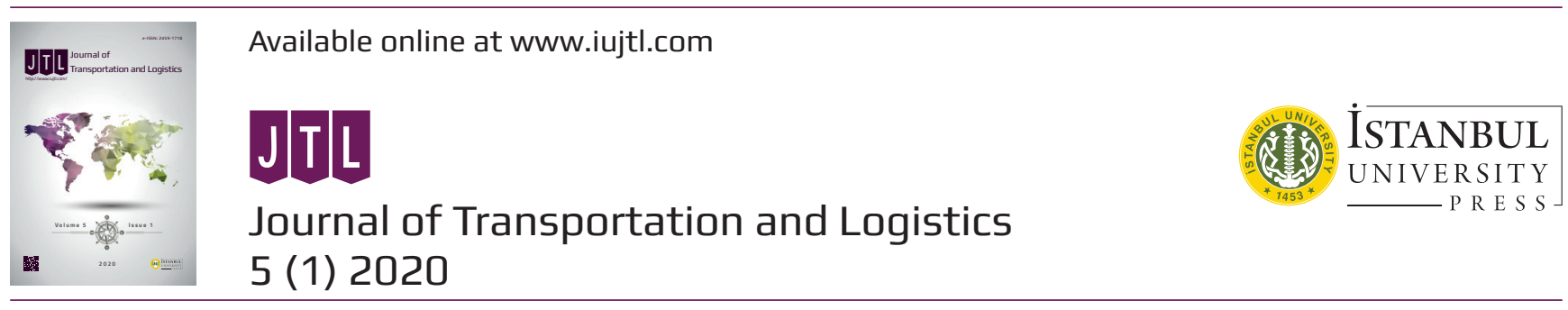

\title{
Tedarikçilerle Süreç Entegrasyonunun Firma Performansı Üzerindeki Etkisinde Ürün Performansının Aracı Rolü
}

\section{The Mediating Role of Product Performance on the Effect of Process Integration with Suppliers on Firm Performance}

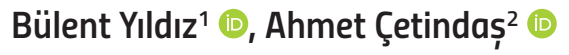

\section{öz}

Bu çalışmada tedarikçilerle süreç entegrasyonunun firma performansı üzerindeki etkisinde ürün performansının aracılık rolü araştııılmıştır. Ayrıca süreç entegrasyonunun firma performansı üzerindeki etkisinde piyasa belirsizliğinin düzenleyici rolü analiz edilmiştir. Bu amaçla İstanbul'da faaliyet gösteren 156 imalat firmasından anket ile veri toplanmıştır. Araştırma kapsamında yapısal eşitlik modeli kurularak analiz edilmiştir. Analiz sonucunda süreç entegrasyonu ve ürün performansının firma performansını pozitif yönde anlamlı olarak etkilediği bulgusuna ulaşıımıştır. Ayrıca ürün performansının da firma performansını pozitif yönde anlamlı olarak etkilediği tespit edilmiştir. Süreç entegrasyonunun firma performansı üzerindeki etkisinde ürün performansının aracılık rolü boostrap yöntemi ile yapılmıştır. Analiz neticesinde ürün performansının aracılık rolü bulunduğu tespit edilmiştir. Araştırma sonucunda piyasa belirsizliğinin düzenleyici rolüne ulaşılamamıştır.

Anahtar Kelimeler: Tedarikçi süreç entegrasyonu, Ürün performansı, Piyasa belirsizliği

\section{ABSTRACT}

This study investigates the mediating role of product performance on the effect of the supplier process integration on Firm performance. Additionally, the moderator effect of market uncertainty on the effect of process integration on firm performance is also analyzed. For this purpose, data were collected by surveys from 156 manufacturing companies operating in Istanbul. A structural equation model was established and analyzed. As a result of the analysis, it was found that process integration had a positive effect on company performance. In addition, it has been determined that product performance has a positive effect on firm performance. The mediation role of product performance on the effect of process integration on firm performance was made by a bootstrap method. The mediating role of product performance could be found but the moderating role of market uncertainty could not be proven.

Keywords: Supplier process integration, Product performance, Market uncertainty

1 Sorumlu yazar/Corresponding author: Bülent Yıldız / Kastamonu Üniversitesi, İktisadi ve İdari Bilimler Fakültesi, İ̧̧letme Bölümü, Kastamonu, Türkiye E-mail: dr.yildiz.bulant@gmail.com, ORCID: 0000-0002-5368-2805

2 Ahmet Çetindaş / Hasan Kalyoncu Üniversitesi- İktisadi İdari ve Sosyal Bilimler Fakültesi, Uluslararası Ticaret ve Lojistik, İstanbul, Türkiye E-mail: ahmet.cetindas@hku.edu.tr, ahmet.cetindass@gmail.com ORCID: 0000-0003-2262-4204

Atıf/Citation: Yildiz, B. \& Cetindas, A. (2020). Tedarikçilerle süreç entegrasyonunun firma performansı üzerindeki etkisinde ürün performansının aracı rolü. Journal of Transportation and Logistics, 5(1), 13-28. https://doi.org/10.26650/JTL.2020.0002 


\section{EXTENDED ABSTRACT}

As emphasized in this study, integration with suppliers is possible with the integration of processes. A process is a set of activities designed to produce a specific output for a particular customer or market (Davenport, 1993). Process integration, on the other hand, refers to the management of various activities that aim to combine relevant business processes within and across companies, and to eliminate duplicate or redundant processes in order to create a better functioning supply chain (Chen vd., 2009).

Process integration with suppliers requires regular communication between cross-organizational work teams and partners. Firm integration ensures that inter-organizational business processes work in collaboration. Thus, it improves firm performance by creating synchronous processes (Frohlich ve Westbrook, 2001) throughout the supply chain and provides operational synergy, resulting in higher productivity.

Mellat-Parast and Spillan (2014) stated that supply chain process integration is the most important indicator of the competitive position of the company, and determined its positive effect on firm competitiveness. Chen et al. (2009) dimensioned process integration with suppliers as internal process integration and external process integration, and found that external process integration positively affects firm performance. Langerak et al. (2007) also investigated the effect of product performance on firm performance, and found a positive effect. Narasimhan and Kim (2002) investigated the moderating effect of market uncertainty in the relationship between planning integration and profitability, and found that profitability increased in markets with low uncertainty. Liao and $\mathrm{Tu}$ (2008) found that the integration of production processes had more impact on production performance under conditions of high environmental uncertainty. For these reasons, the hypotheses of the research are determined as follows.

H1: Process integration with the supplier has a positive effect on firm performance.

$\mathrm{H} 2$ : Process integration with the supplier has a positive effect on product performance.

H3: The effect of process integration on firm performance is mediated by product performance.

H4: Product performance has a positive effect on firm performance.

H5: Market uncertainty has a moderating effect on the effect of Process Integration with Supplier on firm performance.

The research was applied on SMEs operating in Istanbul and Gebze. The sample of the research consists of 156 industrial companies.

Exploratory factor analysis (EFA), confirmatory factor analysis (CFA) and reliability analyzes were performed to test the validity and reliability of the scales. As a result of EFA, factor loads were obtained at over 0.50 for all scales, and $\mathrm{KMO}$ values were obtained at over 0.70. Reliability analysis showed that the alpha coefficient value for all scales was determined by over 0.70 . CFA showed, that the scales meets the goodness of fit criteria. As a result of the correlation analysis, it was found that there was a significant relationship between variables in the same direction at the level of 0.01 significance. 
As a result of structural equation analysis of the model, the process integration with suppliers positively affected product performance and firm performance; It has also been determined that product performance affects firm performance positively.

The bootstrap method was used to test the mediation role of product performance on the impact of process integration with suppliers on firm performance. In order to test the mediating role of product performance, the significance of indirect effects was examined, and the bootstrap method was used for this. The highest likelihood method was used in $95 \%$ confidence interval consisting of 1000 samples and the Monte Carlo parametric bootstrap option was chosen. Indirect effects confidence interval lower value was determined as 0.204, and the confidence interval upper value was found as 0.377. It was found that the significance level of indirect effects is below 0.01 , which means it is meaningful. The fact that the confidence interval lower and upper value ranges do not include zero, and being meaningful indicates that product performance has an intermediary role in the impact of strategic integration with suppliers on firm performance.

Path analysis was conducted to analyze the moderating role of market uncertainty in the impact of process integration with suppliers on firm performance. For this purpose, an interaction variable is formed, which is the multiplication of the process integration and the market uncertainty variables. As a result of the moderating impact analysis, it was seen that process integration and market uncertainty had a positive effect on firm performance. However, the interaction variable did not significantly affect firm performance. This finding shows that market uncertainty has no moderating effect on the effect of process integration on firm performance. The reason for this is thought to be related to the fact that market uncertainty includes a more market-oriented perspective. According to this finding, it will be possible to say that the uncertainties in the market are not related to the procurement processes. As a result of the research, the H1, H2, H3 and H4 hypotheses were supported, while the H5 hypothesis could not be supported. 


\section{Giriş}

İşletmelerin tedarikçileriyle entegre olmaları farklı boyutlarda ve farklı seviyelerde gerçekleşebilmektedir. Bir üretici, stratejik işbirliği yaparak ve firmalar arası süreçleri işbirliği içinde yöneterek tedarikçileriyle entegrasyon sağlayabilir (Flynn vd., 2010).

Entegrasyon, firmaların iş birliği yaparak operasyonel ve stratejik verimlilik elde etmesini sağlar (Rodrigues vd., 2004). Tedarikçi entegrasyonu ise, firmaların tedarikçileriyle örgütler arası stratejileri yapılandırmak, senkronize süreçler geliştirmek ve bilgiyi paylaşmak için işbirliği yaptığında gerçekleşir (Flynn vd., 2010). Tedarikçi entegrasyonu, bir üretici ile tedarikçileri arasındaki bilgi ve fiziksel akışların verimliliğini ve etkinliğini arttırmayı amaçlar; bu da rakiplerine karşı üstünlük elde etmesini, kesintisiz olarak işlemlerini sürdürebilmesini ve uyumlu tedarik ağları kurmasına yardımcı olur (Yeung vd., 2009; Lai vd., 2012; Zhao vd., 2013). Tedarikçi entegrasyonu bir dizi uygulama ve faaliyet içerir ve farklı açılardan incelene bilmektedir. Farklı araştırmacılar tedarikçi entegrasyonunu bilgi paylaşım1, tedarikçilerle uzun vadeli ortaklıklar geliştirme, yeni ürün geliştirmeye tedarikçi katıl1mı, ürün entegrasyonu ve süreç entegrasyonu şeklinde farklı boyutlarda tanımlamaktadır (Swink vd., 2007; Danese ve Romano, 2011; Koufteros vd., 2010; Jayaram, 2008).

Tedarikçilerle entegrasyon bu çalışmada da vurgulandığı üzere süreçlerin entegrasyonuyla mümkün olabilmektedir. Süreç, belirli bir müşteri veya pazar için belirli bir çıktı üretmek üzere tasarlanmış bir faaliyetler bütünüdür (Davenport, 1993). Süreç entegrasyonu ise, şirketler içinde ve genelinde ilgili iş süreçlerini sorunsuz bir şekilde birleştirmeyi ve daha iyi işleyen bir tedarik zinciri oluşturmak amacıyla süreçlerin yinelenen veya gereksiz kısımlarını ortadan kaldırmayı amaçlayan çeşitli faaliyet gruplarının yönetimini ifade eder (Chen vd., 2009)

Tedarikçilerle süreç entegrasyonu, organizasyonlar arası çalışma ekipleri ve ortaklar arasında düzenli iletişim gerektirir. Firma entegrasyonu, organizasyonlar arası iş süreçlerinin işbirliği içinde çalışmasını sağlar. Böylelikle tedarik zinciri boyunca senkronize süreçler yaratarak (Frohlich ve Westbrook, 2001) firma performansını arttırır ve operasyonel sinerji sağlayarak daha yüksek verimlilik ile sonuçlanır.

Tedarikçilerle süreç entegrasyonu, firmaların ortak karar verme ve problem çözmelerini, faaliyetleri koordine etmelerini, ilişkileri sürdürmelerini, olası çatışmaları önlemelerini ve müşterilere daha iyi hizmet vermelerini sağlayan süreçleri senkronize etmelerini kolaylaşt1rır (Palomero ve Chalmeta 2014).

Tedarikçi entegrasyon süreçlerinin ürün performansı üzerindeki etkileri literatürde çok fazla çalışılmamıştır (Lau vd., 2010). Ancak ürün geliştirme literatürü, tedarikçilerin ürün geliştirme sürecine entegre edilmesi durumunda, ürün geliştirme maliyetlerinin düşürülmesine, daha az kusurla daha yüksek kaliteyle üretim yapılmasına ve pazara daha kısa zamanda giriş yapılabileceğini ifade etmektedir.

Pazar belirsizliği kavramı, firmaların faaliyet gösterdiği pazarlarda müşterilerin ve rakiplerin davranışlarının ön görülemediği ve tahmin etmenin zor, hatta imkansız olduğu durumlar için kullanılmaktadır. Pazar belirsizliğini çevresel belirsizliğin bir alt boyutu olarak incele- 
yen birçok çalışma mevcuttur (Wong vd., 2011; Li, 2002). Çünkü hızlı değişimler sonucu şekillenen pazarlarda firmalar bu değişimleri tahmin etmekte zorlanacaktır.

Belirsizliğin yüksek olduğu çalkantılı pazarlarda faaliyet sürdüren firmalar, pazarı yakından takip ederek pazar odaklı tutum sergilediğinde belirsizliğin risklerinden kendini koruyabilmektedir (Jaworski ve Kohli, 1993). Pazar odaklılık müşterilerden ve rakiplerden öğrenme biçimidir (Noble vd., 2002). Pazar odaklılık, müşterilerin ihtiyaçlarını ve rakiplerin eylemlerini izleme ve pazar belirsizliklerine ve karmaşıklıklarına uyum sağlama sürecinin önemli bir parçasıdır (Liu ve Atuahene-Gima, 2018).

Belirsiz taleplerle ilgili olan pazar belirsizliği kavramı bazı yazarlar tarafından talep belirsizliği olarak ele alınmaktadır. Talep belirsizliği stabil olmayan müşteri siparişleri, değiştirilmek durumunda olan üretim planları (Lee vd., 2009: 192) ve farklı müşteri isteklerini karşılamayı gerektirmektedir. Dolayısıyla belirsiz pazarlarda tedarikçisiyle entegre olan firmalar bu ön görülemeyen müşteri davranışlarına hazırlıklı olacak ve tedarikçisiyle entegre ettiği süreçler sayesinde mevcut karmaşıklıkları çözebileceği düşünülmektedir (Bonaccorsi ve Lipparini, 1994; Monczka vd., 2000).

\section{Literatür Taraması ve Araştırma Hipotezlerinin Kurulması}

\subsection{Süreç Entegrasyonunun Ürün ve Firma Performansı Üzerindeki Etkisi}

Birçok çalışma tedarikçi entegrasyonunu performansla ilişkilendirmiş ve anlamlı ilişkiler bulmuştur (Swink vd., 2006; Frohlich ve Westbrook, 2001). Çalışmaların birçoğunda, tedarikçi entegrasyonu tedarik zinciri entegrasyonun bir boyutu olarak ele alınmış ve diğer boyutları olan iç entegrasyon ve müşteri entegrasyonu ile birlikte araştırılmıştır (Wong vd., 2011).

Tedarikçi entegrasyonu, planlamada işbirliği, stratejik ortaklık, ortak ürün geliştirme, bilgi paylaşımı ve bunun gibi iş birliği gerektiren süreçleri içerir (Ettlie ve Reza, 1992; Lai vd., 2010; Ragatz vd., 2002). Mellat-Parast ve Spillan (2014) tedarik zinciri süreç entegrasyonunun, firmanın rekabetçi pozisyonunun en önemli göstergesi olduğunu ifade etmiş ve firma rekabetçiliği üzerine pozitif etkisini saptamıştır. Tedarikçilerle süreç entegrasyonunu iç süreç entegrasyonu ve diş süreç entegrasyonu şeklinde boyutlandıran Chen vd. (2009) diş süreç entegrasyonun firma performansını pozitif yönde etkilediğini bulgulamıştır.

Önceki çalışmalardan yola çıkarak çalışmanın ilk hipotezi aşağıdaki gibi kurulmuştur:

H1: Tedarikçiyle süreç entegrasyonunun firma performansı üzerinde pozitif yönde anlamlı etkisi vardır.

Önceki çalışmalardan anlaşıldığı üzere firma performansının dışında farklı performans türleri de süreç entegrasyonuyla ilişkilendirilmiş̧ir. Lau vd. (2007) 251 Hong Kong firması üzerinde yapmış olduğu araştırmada, tedarik zinciri entegrasyonu sonucu gelişecek olan ortak ürün geliştirme yeteneğini ölçmüş ve ürün performansına etkisini incelemiştir. Sonuçlar tedarikçileriyle ortak ürün geliştirme yapan firmaların daha iyi ürün performansı sergilediğini göstermiştir. Yine Çin'de yapılan bir başka araştırmada ise tedarikçilerle işbirliği yapmanın 
ürün performansına etkisi görülmüştür (Zhang ve Hartley, 2018). Tsai ve Hsu (2014) ise çalışmalarında çapraz departmanlar arasında entegrasyonun ürün performansına etkisini incelemiş ve pozitif yönde anlamlı etkiye rastlamıştır. Tedarikçi performansının ürün performans1 üzerindeki etkisini inceleyen Gatignon ve Xuereb (1997)'da bu etkiyi ispatlayabilmiştir.

Bu çalışmalardan hareketle çalışmamızda tedarikçilerle süreç entegrasyonu firma performansının yanında ürün performansı ile de ilişkilendirilmiştir ve hipotez şu şekilde kurulmuştur:

H2: Tedarikçiyle süreç entegrasyonunun ürün performansı üzerinde pozitif yönde anlamlı etkisi vardır.

\section{2. Ürün Performansının Aracı Rolü ve Firma Performansı Üzerindeki Etkisi}

Çalışmanın bir diğer önemli araştırma konusu olan süreç entegrasyonunun firma performansı üzerindeki etkisinde ürün performansının aracılık rolü ile ilgili bir çalışmaya literatürde rastlanılmamıştır. Ancak Langerak vd. (2007) çalışmasında pazar oryantasyonun firma performansına etkisinde ürün performansının düzenleyici rolünü tespit etmiştir. Tedarikçi entegrasyonu geriye doğru dikey entegrasyonken ve pazar oryantasyonu ileriye doğru dikey entegrasyon olarak görüldüğünden (Waters, 2003), pazar oryantasyonunun firma performansına etkisine aracılık eden ürün performansının tedarikçi entegrasyonu ile firma performansı arasındaki ilişkiye de aracı olarak etki edeceği düşünülmüştür. Yani süreçlerini tedarikçileriyle entegre edebilen firmaların daha yüksek performans gösterme sebebinin ürün performansı dolayısıyla olacağı düşünülmektedir.

Bu sebeple bir sonraki hipotez şu şekilde kurulmuştur:

H3: Süreç entegrasyonunun firma performansina etkisi ürün performansı tarafindan aracllık edilmektedir.

Langerak vd. (2007) ayrıca ürün performansının firma performansı üzerinde etkisini de araştırmış ve pozitif yönde etki bulgulamıştır. Ürün performansının firma performansıyla ilişkili olan müşteri memnuniyetini de etkilediğini gösteren çalışmalar mevcuttur (Agustin ve Singh, 2005; Pan vd., 2012; Rafiq vd., 2013).

Bu sebeple dördüncü hipotez şu şekilde geliştirilmiştir:

H4: Ürün performansinın firma performansı üzerinde pozitif yönde anlamlı etkisi vardır.

\subsection{Piyasa Belirsizliğinin Düzenleyici Rolü}

Piyasa belirsizliği bir diğer adıyla pazar belirsizliği talibin değişken olmasının yanında müşterilerin ve rakiplerinin tutumlarının tahmin edilemediği durumlar için kullanılır. Çalışmamızda olduğu gibi belirsizliği piyasa/pazar belirsizliği (Narasimhan ve Kim, 2002) olarak ele alan çalışmaların yanında, buna çok yakın olan talep belirsizliği (Boon-itt ve Wong 2011; Fynes vd.,2004) ve daha genel olan çevresel belirsizlik (Liao ve Tu, 2008; Stonebraker ve Liao, 2004) olarak ele alan çalışmalar olmuştur. 
Tsai ve Hsu (2014) çalışmalarında departmanlar arasında entegrasyonun ürün performans1na etkisinde pazar belirsizliğine yakın olan rekabet yoğunluğunun düzenleyici rolü olduğunu tespit etmiştir. Narasimhan ve Kim (2002), piyasa belirsizliğinin planlama entegrasyonu ile karlılık arasındaki ilişkide düzenleyici etkisini araştırmış ve belirsizliğin az olduğu pazarlarda karlılığın arttığını bulgulamıştır. O’Leary-Kelly ve Flores (2002), pazarlama-satış planlama kararı entegrasyonunun algılanan kârlılıkla üzerindeki etkisizinde talep belirsizliğinin düzenleyici etkisini tespit etmiştir. Boon-itt ve Wong (2011) talep belirsizliğinin tedarikçi entegrasyonu ile müşteri teslim performansı arasındaki ilişkiyi düzenlediğini bulmuştur. Benzer şekilde Liao ve Tu (2008)'de çevresel belirsizliğin yüksek olduğu koşullarda üretim süreçleri entegrasyonunun üretim performansı üzerindeki etkisinin daha fazla olduğunu bulgulamıştır. Buna göre çalışmanın son hipotezi şöyle geliştirilmiştir:

H5: Tedarikçiyle Süreç entegrasyonunun firma performansı üzerindeki etkisinde piyasa belirsizliğinin düzenleyici etkisi bulunmaktadır.

\section{Araştırmanın Yöntemi}

Kuramsal çalışma ve literatür taraması neticesinde kurulan araştırma modeli Şekil 1'de verilmiştir.

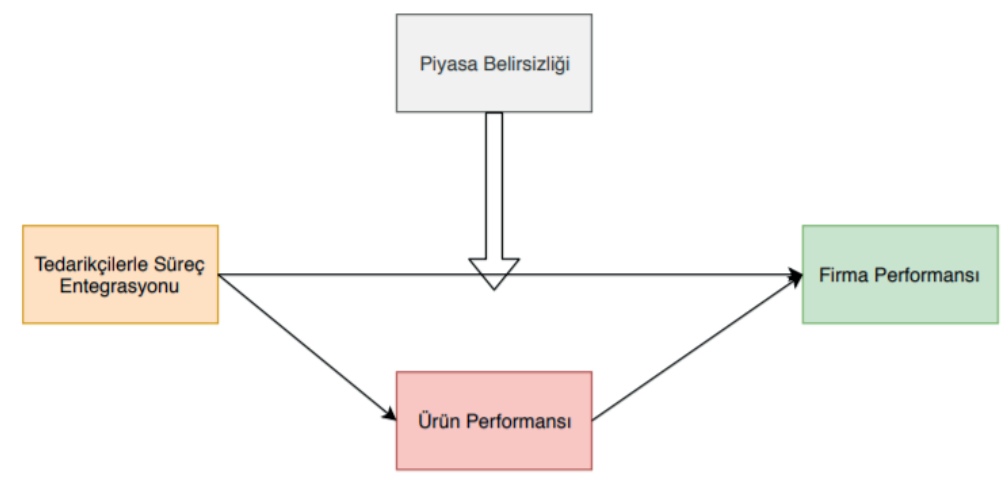

Şekil 1. Araştırmanın modeli

Araştırma İstanbul ve Gebze'de faaliyette bulunan KOBI'ler üzerinde yapılmıştır. Araştırmanın örneklemini 156 sanayi firması oluşturmaktadır. Araştırmaya katılan firmaların 89'u gıda, 18'i tekstil, 11'i otomotiv ve yedek parça, 6's1 ambalaj, 6'sı makine, 5'i elektronik, 5'i elektrik, 4'ü kimya, 3'ü bilgisayar, 3'ü inşaat, 3'ü mobilya, 2'si enerji ve 1'i paketleme sektörlerinde faaliyet göstermektedir. Firmaların 80'i 6-15 yıl arası, 65'i 16 yıl ve üzeri, 11 'i ise 0-5 yıl aras faaliyette bulunmaktadır. Firmaların 105'i 0-51 aras1 ve 51'i de 51-150 arasi personel çalıştırmaktadır. Anketi cevaplandıran firma çalışanlarının 65'i satın alma, 53'ü pazarlama, 19'u üretim, 8'i dış ticaret departmanlarında görev yapmakta olup 11'i de yönetim kurulu üyesidir. Çalışanların 71'i 0-5 yıl arası, 64'ü 6-15 yıl arası ve 21'i de 16 yıl ve üzeri firmada görev yapmaktadır. Çalışanların 121'i üniversite, 33'ü lise ve 2'si de ilköğretim mezunudur.

Araştırmada öncelikle keşfedici faktör analizi (KFA), doğrulayıcı faktör analizi (DFA) ve güvenilirlik analizleri yapılarak ölçeklerin yapı geçerliği ve güvenilirliği test edilmiştir. 
Tedarikçilerle süreç entegrasyonu ölçeğinin KFA ve güvenilirlik analizi sonuçları Tablo 1'de verilmiştir.

Tablo 1. Süreç entegrasyonu faktör yükleri ve güvenilirlik analizi

\begin{tabular}{|l|c|}
\hline Maddeler & Faktör Yükü \\
\hline TSE1: Ürün tasarım ve geliştirme aşamasında ana tedarikçileri işe dahil ederiz &, 880 \\
\hline TSE2: Proje ekiplerimizde ana tedarikçi üyeliği / katılımı vardır &, 884 \\
\hline TSE3: Şirketimiz, üretim planlama ve stok yönetimi konularında tedarikçileri işe dahil eder &, 837 \\
\hline TSE4: Ortak sorunları çözme konusunda ana tedarikçileri işe dahil ederiz &, 836 \\
\hline KMO: 0,809 Top. Açk. Varyans: \%73,891 Alfa: 0,882 AVE: 0,737 CR: 0,919 & \\
\hline
\end{tabular}

KFA sonucu süreç entegrasyonu ölçeğinin faktör yükleri 0,836 ile 0,880 aralığında elde edilmiştir. KMO değeri 0,809 olarak bulunmuştur ve $\mathrm{p}<0,01$ olarak elde edilmiştir. Bu bulgu örneklem büyüklüğünün faktör analizi için uygun olduğunu göstermektedir. Ölçeğin toplam varyansın \%73,891'ini açıkladığı tespit edilmiştir. Güvenilirlik analizi sonucu alfa katsayısı 0,882 olarak bulunmuştur. Bu bulgu ölçeğin güvenilir olduğunu göstermektedir. AVE değeri 0,50'nin üzerinde, CR değeri 0,70'in üzerinde ve CR değeri de AVE değerinden yüksek olarak elde edilmiştir. Bu bulgu da ölçeğin bileşen geçerliğini sağladığını göstermektedir.

Ürün performansı ölçeğinin KFA ve güvenilirlik analizi sonuçları Tablo 2'de verilmiştir.

Tablo 2. Ürün performansı faktör yükleri ve güvenilirlik analizi

\begin{tabular}{|l|c|}
\hline Maddeler & Faktör Yükü \\
\hline UP1: Ana ürünümüz, satış hedefimize ulaştı. &, 946 \\
\hline UP2: Ana ürünümüz, kar hedefimize ulaştı. &, 930 \\
\hline UP3: Ana ürünümüz, büyük karlılık getirdi. &, 884 \\
\hline UP4: Müşteriler, ana ürünümüzün performansından çok memnunlar. &, 888 \\
\hline KMO: 0,932 Top. Açk. Varyans: \%83,263 Alfa: 0,932 AVE: 0,83 CR: 0,952 & \\
\hline
\end{tabular}

KFA sonucu ürün performansı ölçeğinin faktör yükleri 0,884 ile 0,946 aralığında elde edilmiştir. KMO değeri 0,932 olarak bulunmuştur ve $\mathrm{p}<0,01$ olarak elde edilmiştir. Bu bulgu örneklem büyüklüğünün faktör analizi için uygun olduğunu göstermektedir. Ölçeğin toplam varyansın \%83,236'sını açıkladığı tespit edilmiştir. Güvenilirlik analizi sonucu alfa katsayısı 0,932 olarak bulunmuştur. Bu bulgu ölçeğin güvenilir olduğunu göstermektedir. AVE değeri 0,50'nin üzerinde, CR değeri 0,70'in üzerinde ve CR değeri de AVE değerinden yüksek olarak elde edilmiştir. Bu bulgu da ölçeğin bileşen geçerliğini sağladığını göstermektedir.

Firma performansı ölçeğinin KFA ve güvenilirlik analizi sonuçları Tablo 3 'de verilmiştir.

Tablo 3. Firma performansı faktör ve güvenilirlik analizi

\begin{tabular}{|l|c|}
\hline Maddeler & Faktör Yükü \\
\hline FP1: Firmamız pazar payında bir artış sağlamıştır &, 903 \\
\hline FP2: Firmamız satı̧̧larda bir artış sağlamıştır &, 897 \\
\hline FP3: Firmamız yatırımın geri dönüşünde bir artış sağlamıştır &, 851 \\
\hline FP4: Firmamız satışların geri dönüşünde bir artış sağlamıştır &, 856 \\
\hline FP5: Firmamız genel rekabetçi konumunda bir artışa ulaşmıştır &, 638 \\
\hline KMO: 0,836 Top. Açk. Varyans: \%69,712 Alfa: 0,890 AVE: 0,696 CR: 0,918 & \\
\hline
\end{tabular}


KFA sonucu ürün performansı ölçeğinin faktör yükleri 0,638 ile 0,903 aralığında elde edilmiştir. KMO değeri 0,836 olarak bulunmuştur ve $p<0,01$ olarak elde edilmiştir. Bu bulgu örneklem büyüklüğünün faktör analizi için uygun olduğunu göstermektedir. Ölçeğin toplam varyansın \%69,712'sini açıkladığı tespit edilmiştir. Güvenilirlik analizi sonucu alfa katsayısı 0,890 olarak bulunmuştur. Bu bulgu ölçeğin güvenilir olduğunu göstermektedir. AVE değeri 0,50'nin üzerinde, CR değeri 0,70'in üzerinde ve CR değeri de AVE değerinden yüksek olarak elde edilmiştir. Bu bulgu da ölçeğin bileşen geçerliğini sağladığını göstermektedir.

Piyasa Belirsizliği ölçeğinin KFA ve güvenilirlik analizi sonuçları Tablo 4'de verilmiştir.

Tablo 4. Piyasa belirsizliği faktör yükleri ve güvenilirlik analizi

\begin{tabular}{|l|c|}
\hline Maddeler & Faktör Yükü \\
\hline PB1: Rekabetçi piyasa koşullarının öngörülemezliği oldukça yüksektir. &, 884 \\
\hline PB2: Piyasalardaki rakip faaliyetleri oldukça belirsizdir. &, 889 \\
\hline PB3: Müşteri ürün talebi ve tercihleri oldukça belirsizdir. &, 847 \\
\hline PB4: Müşteri gereksinimleri ve tercihlerindeki değişiklikleri öngörüp tahmin etmek zordur. &, 859 \\
\hline PB5: Müşteri gereksinimlerindeki değişiklikler oldukça öngörülemez ve belirsizdir. &, 849 \\
\hline KMO: 0,877 Top. Açk. Varyans: \%74,957 Alfa: 0,916 AVE: 0,75 CR: 0,937 & \\
\hline
\end{tabular}

KFA sonucu ürün performansı ölçeğinin faktör yükleri 0,847 ile 0,889 aralığında elde edilmiştir. KMO değeri 0,877 olarak bulunmuştur ve $p<0,01$ olarak elde edilmiştir. Bu bulgu örneklem büyüklüğünün faktör analizi için uygun olduğunu göstermektedir. Ölçeğin toplam varyansın \%74,957'sini açıkladığı tespit edilmiştir. Güvenilirlik analizi sonucu alfa katsayısı 0,916 olarak bulunmuştur. Bu bulgu ölçeğin güvenilir olduğunu göstermektedir. AVE değeri 0,50'nin üzerinde, CR değeri 0,70'in üzerinde ve CR değeri de AVE değerinden yüksek olarak elde edilmiştir. Bu bulgu da ölçeğin bileşen geçerliğini sağladığını göstermektedir.

KFA ve güvenilirlik analizinden sonra DFA yapılmıştır. DFA sonucu ölçekler için elde edilen uyum iyiliği değerleri Tablo 5'de verilmiştir.

Tablo 5. DFA uyum iyiliği değerleri

\begin{tabular}{|l|c|c|c|c|c|c|c|}
\hline Değişken & CMIN & DF & CMIN/DF & GFI & CFI & TLI & RMSEA \\
\hline Tedarikçilerle Süreç Entegrasyonu & 1,953 & 1 & 1,953 & 0,994 & 0,997 & 0,983 & 0,078 \\
\hline Ürün Performans1 & 0,288 & 1 & 0,288 & 0,999 & 1 & 1 & 0 \\
\hline Firma Performans1 & 3,695 & 4 & 0,924 & 0,990 & 1 & 1 & 0 \\
\hline Piyasa Belirsizliği & 4,846 & 4 & 1,211 & 0,988 & 0,998 & 0,996 & 0,037 \\
\hline
\end{tabular}

DFA neticesinde faktör yükleri tedarikçilerle süreç entegrasyonu ölçeği için 0,713 ile 0,884 aralığında; ürün performansı ölçeği için 0,802 ile 0,970 aralığında; firma performansı ölçeği için 0,545 ile 0,903 aralığında ve piyasa belirsizliği ölçeği için ise 0,786 ile 0,897 aralığında elde edilmiştir. CMIN/df değerlerinin 5'in altında bulunması, RMSEA değerlerinin 0,08'in altında elde edilmesi, GFI, CFI ve TLI değerlerinin de 0,95 'in üzerinde elde edilmiş olması ölçeklerin kabul edilebilir uyum iyiliği kriterlerini sağladığını göstermektedir.

KFA, DFA ve güvenilirlik analizinden sonra değişkenler arasındaki ilişkiyi görebilmek için korelasyon analizi yapılmıştır. Korelasyon analizine ilişkin bulgular Tablo 6'da verilmiştir. 
Tablo 6. Korelasyon analizi

\begin{tabular}{|l|c|c|c|c|c|c|}
\hline & Ort. & Std. Sapma & Firma Performansı & Süreç Entegrasyonu & Ürün Performansı & Piyasa Belirsizliği \\
\hline Firma Performans1 & 4,1064 &, 62853 & 1 & & & \\
\hline Süreç Entegrasyonu & 3,9455 &, 72195 &, $682^{* *}$ & 1 & & \\
\hline Ürün Performansı & 4,0962 &, 68830 &, $720^{* *}$ &, $483^{* *}$ & 1 &, $337^{* *}$ \\
\hline Piyasa Belirsizliği & 3,8590 &, 74356 &, $455^{* *}$ &, $621^{* *}$ & 1 \\
\hline
\end{tabular}

Korelasyon analizi sonucu değişkenler arasında 0,01 anlamlılık düzeyinde aynı yönde anlamlı bir ilişki olduğu bulgusuna ulaşılmıştır. Değişkenlerin ortalama değerlerine bakıldığında cevap ortalamalarının yüksek olduğu görülmektedir.

Araştırma hipotezlerini test etmek amacıyla öncelikli olarak yapısal eşitlik modeli kurularak analiz edilmiştir. Analiz edilen model Şekil 2'de, yapısal eşitlik modelinin analizi sonucu ulaşılan uyum iyiliği değerleri Tablo 7'de ve analiz sonuçları Tablo 8'de verilmiştir.

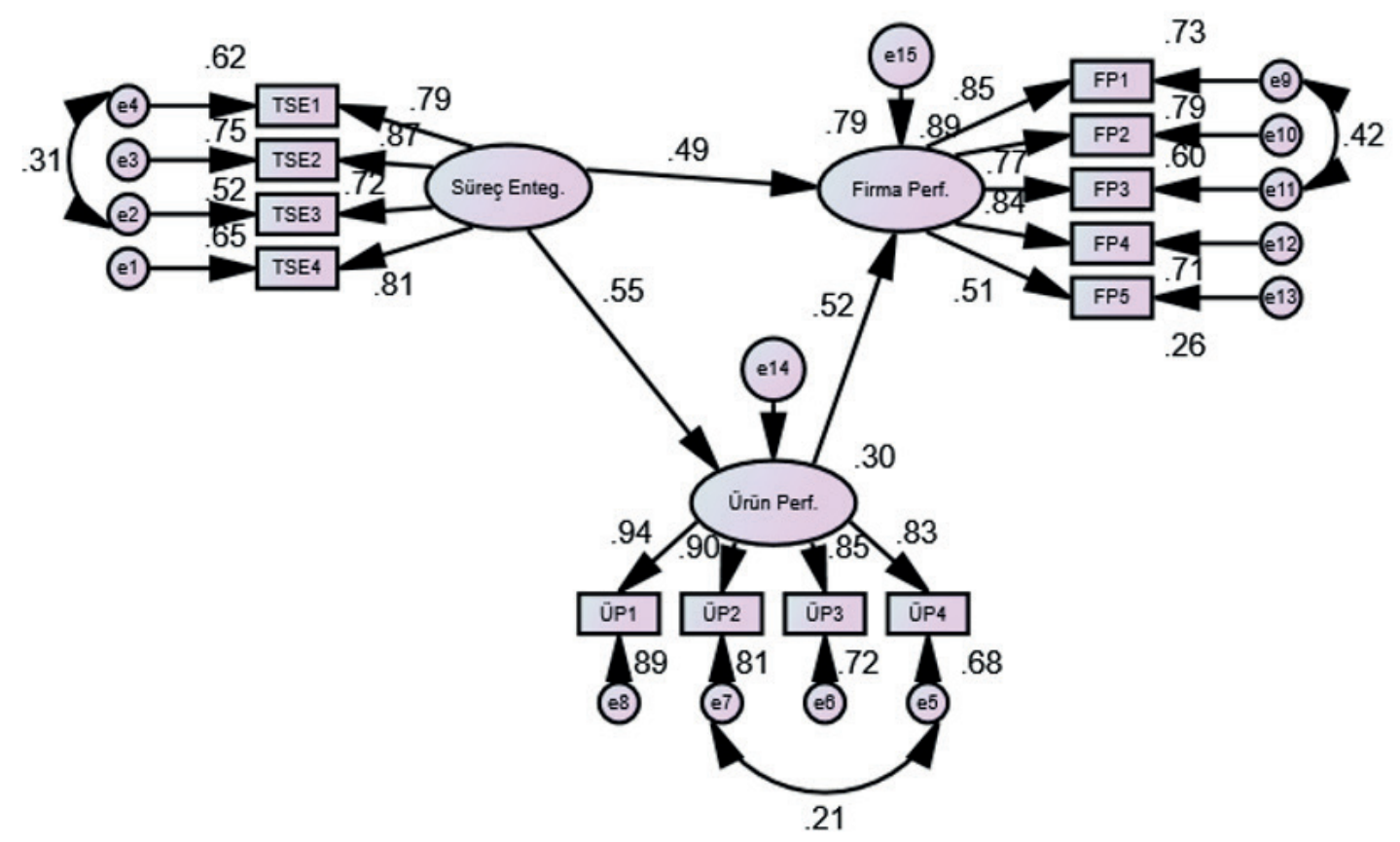

Şekil 2. Yapısal eşitlik modeli

Şekil 2'de görüleceği gibi araştırma kapsamında öncelikle tedarikçilerle süreç entegrasyonunun ürün performansı ve firma performansı üzerindeki etkisi ile ürün performansının firma performansı üzerindeki etkisi analiz edilmiştir. Uyum iyiliği değerlerini elde edebilmek için süreç entegrasyonu ölçeğinin 1. ve 3. maddeleri arasında, ürün performansı ölçeğinin 2. ve 4. maddeleri arasında, firma performansı ölçeğinin de 1. ve 2. maddeleri arasında modifikasyon yapılmıştır. 
Tablo 7. Yapısal eşitlik modeli uyum iyiliği değerleri

\begin{tabular}{|l|l|l|l|l|l|l|l|}
\hline Değişken & CMIN & DF & CMIN/DF & GFI & CFI & TLI & RMSEA \\
\hline Yapıssal Eşitlik Modeli & 108,613 & 56 & 1,94 & 0,904 & 0,974 & 0,963 & 0,078 \\
\hline
\end{tabular}

Yapısal eşitlik modelinin analizi sonucu CMIN/df değerlerinin 5'in altında bulunması, RMSEA değerlerinin 0,08'in altında elde edilmesi, CFI ve TLI değerlerinin de 0,95'in üzerinde elde edilmiş olması modelin kabul edilebilir uyum iyiliği kriterlerini sağladığını göstermektedir.

Tablo 8. Yapısal eşitlik modeli analiz sonuçları

\begin{tabular}{|l|c|c|c|c|c|c|c|}
\hline \multicolumn{3}{|c|}{ Analiz Edilen Yol } & $\begin{array}{c}\text { Standardize } \\
\text { Edilmemiş }\end{array}$ & $\begin{array}{c}\text { Standardize } \\
\text { Edilmiş }\end{array}$ & Std. Hata & $\begin{array}{c}\text { Kritik } \\
\text { Oran }\end{array}$ & P \\
\hline $\begin{array}{l}\text { Ürün } \\
\text { Performans1 }\end{array}$ & $<---$ & $\begin{array}{c}\text { Süreç } \\
\text { Entegrasyonu }\end{array}$ & 0,514 & 0,549 & 0,083 & 6,181 & $* * *$ \\
\hline $\begin{array}{l}\text { Firma } \\
\text { Performans1 }\end{array}$ & $<---$ & $\begin{array}{c}\text { Süreç } \\
\text { Entegrasyonu }\end{array}$ & 0,449 & 0,485 & 0,069 & 6,501 & $* * *$ \\
\hline $\begin{array}{l}\text { Firma } \\
\text { Performans1 }\end{array}$ & $<---$ & Ürün Performans1 & 0,515 & 0,522 & 0,072 & 7,108 & $* * *$ \\
\hline
\end{tabular}

Yapısal eşitlik modelinin analizi sonucunda tedarikçilerle süreç entegrasyonunun ürün performansı ve firma performansını pozitif yönde anlamlı olarak etkilediği; ürün performansının da fïma performansını pozitif yönde anlamlı olarak etkilediği tespit edilmiştir. Anlamlılık düzeyi her biri için sıfıra çok yakın olarak bulunmuştur. Tablo 8'de *** ifadesi sıfıra çok yakın bir değeri göstermektedir. Süreç entegrasyonunun ürün performansı üzerindeki etkisinde standardize edilmiş katsayı tahmin değeri 0,549 olarak bulunmuştur. Bu bulgu süreç entegrasyonunun 1 birim artması durumunda ürün performansının 0,549 birim artacağını göstermektedir. Süreç entegrasyonunun firma performansı üzerindeki etkisinde standardize edilmiş katsayı tahmin değerinin 0,485 olarak elde edilmiş olması süreç entegrasyonunun 1 birim artması durumunda firma performansının 0,485 birim artış göstereceği anlamlına gelmektedir. Ürün performansının firma performansı üzerindeki etkisinde tahmin değeri 0,522 olarak elde edilmiştir. Bu sonuç ürün performansının 1 birim artış göstermesi durumunda firma performansının 0,522 birim artış göstereceği anlamlına gelmektedir. Kritik oran değerlerinin de 1,96'nın üzerinde elde edilmiş olması aynı zamanda test edilen yolun istatistiksel olarak anlamlı olduğunu göstermektedir.

Tedarikçilerle süreç entegrasyonunun firma performansı üzerindeki etkisinde ürün performansının aracılık rolünü test edebilmek için Şekil 2'de verilmiş olan yapısal eşitlik modelinde bootstrap yöntemi kullanılmıştır. Ürün performansının aracılık rolünü test edebilmek için dolaylı etkilerin anlamlılığına bakılmış ve bunun için ise bootsrap yöntemi kullanılmıştır. 1000 örneklemden oluşan \% 95 güven aralığında en yükssek olabilirlik yöntemi kullanılmış ve monte carlo parametrik bootsrap seçeneği seçilmiştir. Bootsrap güven aralığı alt değerleri (Lower Bounds) ve güven aralı̆̆1 üst değerleri (Upper Bounds) ile Bootsrap standardize edilmiş dolaylı etkiler bulguları Tablo 9' da verilmiştir. 
Tablo 9. Ürün performansı aracılık testi sonuçları

\begin{tabular}{|l|c|}
\hline Standardize Edilmiş Toplam Etkiler & Tedarikçilerle Süreç Entegrasyonu \\
\hline Ürün Performansı & 0,549 \\
\hline Firma Performansı & 0,772 \\
\hline Toplam Etkiler Anlamlıık & 0,003 \\
\hline Ürün Performansı & 0,003 \\
\hline Firma Performansı & 0,669 \\
\hline Toplam Etkiler Güven Aralığı Alt Değeri & 0,847 \\
\hline Toplam Etkiler Güven Aralığı Üst Değeri & \\
\hline Standardize Edilmiş Doğrudan Etkiler & 0,665 \\
\hline Ürün Performansı & 0,611 \\
\hline Firma Performansı & \\
\hline Doğrudan Etkiler Anlamlıık & 0,003 \\
\hline Ürün Performansı & 0,002 \\
\hline Firma Performansı & 0,347 \\
\hline Doğrudan Etkiler Güven Aralığı Alt Değeri & 0,611 \\
\hline Doğrudan Etkiler Güven Aralığı Üst Değeri & \\
\hline Standardize Edilmiş Dolaylı Etkiler & 0,377 \\
\hline Firma Performansı & \\
\hline Dolaylı Etkiler Anlamlılık & 0,002 \\
\hline Firma Performansı & 0,204 \\
\hline Dolaylı Etkiler Güven Aralığı Alt Değerleri & 0,377 \\
\hline Dolaylı Etkiler Güven Aralığı Üst Değerleri & \\
\hline
\end{tabular}

Tablo 9'da görüldüğü üzere standardize edilmiş dolaylı etkiler 0,377 olarak elde edilmiştir. Dolaylı etkiler güven aralığı alt değeri 0,204 ve güven aralığı üst değeri 0,377 olarak tespit edilmiştir. Dolaylı etkilerin anlamlılık düzeyinin de 0,01'in altında olduğu yani anlamlı olduğu bulgusuna ulaşılmıştır. Güven aralığı alt ve üst değer aralığının sıfır değerini kapsamaması ve anlamlı olması tedarikçilerle stratejik entegrasyonun firma performansı üzerindeki etkisinde ürün performansının aracılık rolü bulunduğunu göstermektedir.

Tedarikçilerle süreç entegrasyonunun firma performansı üzerindeki etkisinde piyasa belirsizliğinin düzenleyici rolünü analiz edebilmek için yol analizi yapılmıştır. Bu amaçla öncelikle süreç entegrasyonu ve piyasa belirsizliği değişkenlerinin çarpımından oluşan bir etkileşim değişkeni oluşturulmuştur. Analiz edilen düzenleyici etki modeli Şekil 3'de verilmiştir. Analiz sonuçları ise Tablo 10’ da sunulmuştur.

Şekil 3'de görüleceği gibi süreç entegrasyonunun, piyasa belirsizliğinin ve bu iki değişkenin çarpımından oluşan etkileşim değişkeninin firma performansı üzerindeki etkisi analiz edilmektedir.

Tablo 10. Düzenleyici etki analizi

\begin{tabular}{|l|c|c|c|c|c|c|c|}
\hline \multicolumn{3}{|c|}{ Analiz Edilen Yol } & $\begin{array}{c}\text { Standardize } \\
\text { Edilmemiş }\end{array}$ & $\begin{array}{c}\text { Standardize } \\
\text { Edilmiş }\end{array}$ & Std. Hata & Kritik Oran & P \\
\hline $\begin{array}{l}\text { Firma } \\
\text { Performans1 }\end{array}$ & $<---$ & $\begin{array}{c}\text { Süreç } \\
\text { Entegrasyonu }\end{array}$ & 0,611 & 0,685 & 0,051 & 11,963 & $* * *$ \\
\hline $\begin{array}{l}\text { Firma } \\
\text { Performans1 }\end{array}$ & $<---$ & Piyasa Belirsizliği & 0,099 & 0,114 & 0,05 & 1,988 & 0,047 \\
\hline $\begin{array}{l}\text { Firma } \\
\text { Performans1 }\end{array}$ & $<---$ & Etkileşim & $-0,014$ & $-0,104$ & 0,008 & $-1,818$ & 0,069 \\
\hline
\end{tabular}




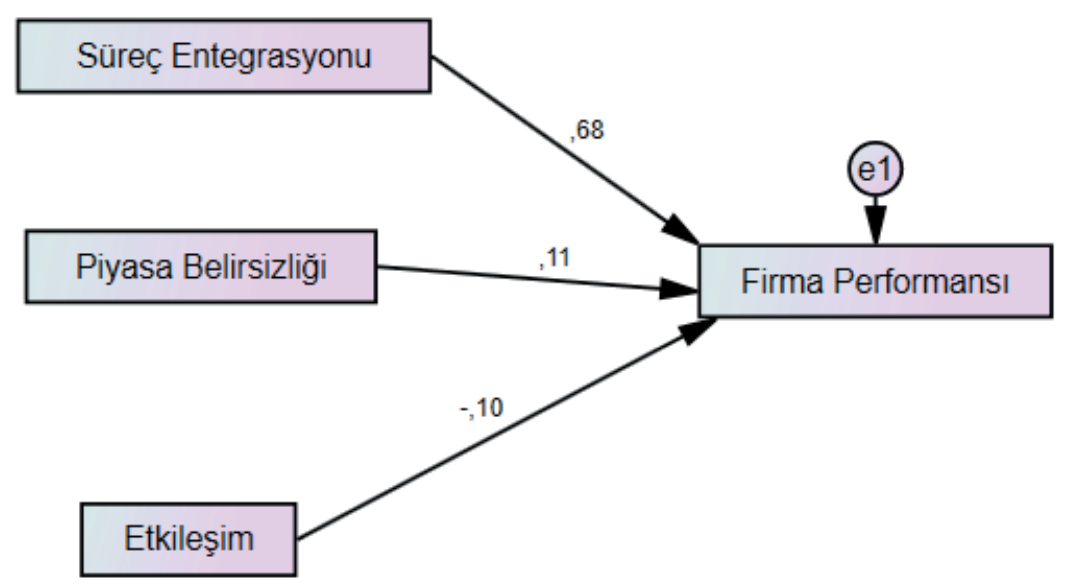

Şekil 3. Düzenleyici etki modeli

Düzenleyici etki analizi sonucu süreç entegrasyonunun ve piyasa belirsizliğinin firma performansını pozitif yönde anlamlı olarak etkilediği görülmüştür. Fakat etkileşim değişkeni firma performansını anlamlı olarak etkilememiştir. Bu bulgu süreç entegrasyonunun firma performansı üzerindeki etkisinde piyasa belirsizliğinin düzenleyici rolü olduğu bulgusuna ulaşılamadığı bilgisini vermektedir. Zaten Tablo 10'da raporlandığı gibi etkileşim değişkeninin firma performansı üzerindeki etkisinin analizi sonucu kritik oran değeri de mutlak değer içerisinde 1,96'dan küçük bir değer olarak bulunmuştur. Bu bulguda etkinin anlamlı olmadığını göstermektedir. Anlamlılık düzeyi de 0,05 'in üzerinde bulunduğundan dolayı da etki anlamsızdır.

\section{Sonuç}

Tedarikçi entegrasyonu uzun zamandır araştırılan ve firmaların performansını arttırabilecek bir yöntem olarak önerilen bir stratejidir. Firmaların tedarikçileriyle entegrasyonu literatürde farklı açılardan incelenmektedir. Bu çalışmada süreç entegrasyonu araştırılmış ve firma performansına direk ve ürün performansı aracılığıyla etkisi incelenmiştir.

Çalışmanın bulguları tedarikçileriyle süreçlerini entegre eden firmaların daha yüksek performans gösterdiği ve süreç entegrasyonun firma performansına etkisinde ürün performansının bu ilişkiye aracılık ettiği görülmüştür. Tedarikçilerini üretim planlama, ürün tasarımı, stok yönetimi ve bu konularda çıkacak problemlerin çözümlenmesine dahil eden firmalar tedarikçileriyle süreçlerini entegre etmiş olacak ve malzeme tedarikinde daha az sorun yaşayacağından daha yüksek performans gösterecektir. Süreçlerini tedarikçileriyle entegre etmiş olan firmalar onları ürün geliştirme süreçlerine dahil ederek ürün performansını arttırabileceği bunun da firma performansını arttıracă̆1 ispatlanmıştır (H1-H2-H3). Bu çalışmanın ilk üç hipotezini doğrulamaktadır.

Ürün performansının firma performansına etkisi (H4) ile ilgili literatürde tatmin edici miktarda çalışmaya rastlanılmamıştır. Bir tane ürün performansının firma performansına etkisini araştıran çalışma (Langerak vd., 2007) ve birkaç tane ürün performansının müşteri memnuniyetine etkisini araştıran çalışmalara rastlanılmıştır (Pan vd., 2012; Rafiq vd., 2013). Bu çalışmalarla paralel sonuçlar bulunan çalışmamızda firmaların yüksek performans gösteren ürünlerine sahip olmasının firma performansını arttıracağı ispatlanmıştır (H4). Bu çalışmanın dördüncü hipotezini doğrulamaktadır. 
Süreç entegrasyonunun firma performansını nasıl etkileyeceğinin yanında piyasa belirsizliğinin bu etkiyi nasıl düzenleyeceği de ayrıca merak konusu olmuş ve bu amaçla (H5) hipotez kurulmuştur. Ancak piyasa belirsizliğinin süreç entegrasyonu ile firma performansı arasındaki ilişkide düzenleyici rolü olmadığı bulgulamıştır. Bunun sebebinin piyasa belirsizliğinin daha pazar odaklı bir bakış açısı içerdiği ile ilgili olduğu düşünülmektedir. Bu bulguya göre pazarda oluşacak belirsizliklerin tedarik süreçleriyle ilgisinin olmadığını söylemek mümkün olacaktır.

Çalışmamız gösteriyor ki tedarikçileriyle süreçlerini entegre eden firmalar daha yüksek ürün performansı ve bunun aracılığıyla daha yüksek firma performansı göstermektedir. $\mathrm{Bu}$ sebeple firmalara tedarikçilerini süreçlerine dahil etmesi gerektiği önerilmektedir. Bu şekilde firmaların tedarikçileri ürün geliştirme, planlama gibi süreçlere dahil ederek daha yüksek performans gösteren ürünlere sahip olacakları ve bunun da firma performansının artmasına aracı olacağı konusunda firmalara öneriler yapılabilmektedir.

Çalışmamız literatüre tedarikçilerle süreç entegrasyonun firma performansına etki ettiği ve ürün performansının bu etkiye aracılık ettiği bulgusuyla katkı sağlamıştır. Pazar belirsizliğinin düzenleyici etkisi ispatlanamadığından gelecekte pazar odaklı bir belirsizlik yerine daha çok işletmenin genel çevresini veya üretim çevresini temel alan değişkenlerle bu etkiye tekrar bıkılması araştırmacılara önerilmektedir. Ayrıca literatürde süreç entegrasyonu d1şında farklı entegrasyon boyutları kullanıldığı görülmüştür. Gelecekte bu boyutlarında firma performansına direkt etkisi ve ürün performansı üzerinden etkisinin incelenmesi literatüre daha fazla katkı sağlayacaktır.

Hakem Değerlendirmesi: Dış bağımsız.

Çıkar Çatışması: Yazarlar çıkar çatışması bildirmemiştir.

Finansal Destek: Yazarlar bu çalışma için finansal destek almadığını beyan etmiştir.

Peer-review: Externally peer-reviewed.

Conflict of Interest: The authors have no conflict of interest to declare.

Grant Support: The authors declared that this study has received no financial support.

\section{Kaynaklar}

Agustin, C. \& Singh, J. (2005). Curvilinear effects of consumer loyalty determinants in relational exchanges, Journal of Marketing Research 42;96-108.

Boon-itt, S. \& Wong, C.Y. (2011). The moderating effects of technological and demand uncertainties on the relationship between supply chain integration and customer delivery performance. International Journal of Physical Distribution and Logistics Management. 41(3),253-276.

Bonaccorsi, A. \& Lipparini, A. (1994). Strategic partnerships in new product development: an italian case study. Journal of Product Innovation Management 11:134-145.

Chen, H., Daugherty, P. J., ve Roath, A. S. (2009). Defining and operationalizing supply chain process integration. Journal of Business Logistics, 30(1), 63-84

Danese, P. \& Romano, P. (2011). Supply chain integration and efficiency performance: a study on the interactions between customer and supplier integration, Supply Chain Management: An International Journal, 16(4),220-230.

Davenport, T.H. (1993), Process innovation-reengineering work through information technology. Harvard Business School Press, Boston, MA. 
Ettlie, J.E. \& Reza, E., (1992). Organizational integration and process innovation. Academy of Management Journal 34, 795-827.

Flynn, B. B., B. Huo, \& X. Zhao. (2010). The impact of supply chain integration on performance: a contingency and configuration approach. Journal of Operations Management, 28(1),58-71.

Fynes, B., Burca, S. \& Marshall, D. (2004). Environmental uncertainty, supply chain relationship quality and performance. Journal of Purchasing and Supply Management, 10, 179-190.

Frohlich, M. T. \& R. Westbrook. 2001. Arcs of integration: An international study of supply chain strategies. Journal of Operations Management. 19 (2), 185-200.

Frohlich, M.T. \& Westbrook, R. (2001). Arcs of integration: An international study of supply chain strategies. Journal of Operation Management. 19:185-200.

Gatignon, H. \& Xuereb, J.M. (1997). Strategic orientation of the firm and new product performance. Journal of Marketing Research. 34, 77-90.

Gatignon, H. \& Xuereb, J. (1997). Strategic orientation of the firm and new product performance. Journal of Marketing Research, 34(1), 77-90.

Jayaram, J. (2008). Supplier involvement in new product development projects: dimensionality and contingency effects". International Journal of Production Research. 46(13), 3717-3735.

Jaworski, B.J. \& Kohli, A.K. (1993). Market orientation: Antecedents and consequences. Journal of Marketing. 57(3),53-70.

Koufteros, X.A., Rawski, G.E. \& Rupak, R. (2010), Organizational integration for product development: the effects on glitches, on-time execution of engineering change orders, and market success. Decision Sciences, 41(1), 49-80.

Lai, F., M. Zhang, D.M.S. Lee \& X. Zhao. (2012). the impact of supply chain integration on mass customization capability: An extended resourcebased view. IEEE Transactions on Engineering Management. 59(3), 443-456.

Lai, K.H., Wong, C.W.Y. \& Cheng, T.C.E. (2010). Bundling digitized logistics activities and its performance implications. Industrial Marketing Management. 39(2), 273-286.

Langerak, F. Hultink, E.J. \& Robben; H.S.J. (2007). The mediating role of new product development in the link between market orientation and organizational performance, Journal of Strategic Marketing. 15(4), 281-305

Lau, A., Yam, R. \& Tang, E. (2007). Supply chain product co $\square$ development, product modularity and product performance. Industrial Management and Data Systems. 107(7), 1036-1065.

Lau, A.K.W., Tang, E. \& Yam, R.C.M. (2010). Effects of supplier and customer integration on product innovation and performance: empirical evidence in Hong Kong manufacturers. Journal of Product Innovation Management. 27(5),761-777.

Lee, P.K.C., Yeung, A.C.L. \& Cheng, T.C.E. (2009). Supplier alliances and envioronmental uncertainty: An emprical study, 1n. J. Production Economics. 120, 190-204.

Li, S. (2002). An integrated model for supply chain management practices, performance and competitive advantage. Unpublished Doctoral Dissertation, University of Toledo, Toledo.

Liao, K. \& Tu, Q. (2008). Leveraging automation and integration to improve manufacturing performance under uncertainty. Journal of Manufacturing Technology Management. 19(1) 38-51.

Liu, W. \& Atuahene-Gima, K. (2018). Enhancing product innovation performance in a dysfunctional competitive environment: The roles of competitive strategies and market-based assets. Industrial Marketing Management. (73), 7-20.

Mellat-Parast, M. \& Spillan, J. (2014), Logistics and supply chain process integration as a source of competitive advantage. International Journal of Logistics Management. 25(2), 289-314

Monczka, R.M., Handfield, R.B., Scannell, T.V., Ragatz, G.L. \& Frayer, D.L. (2000). New product development strategies for supplier integration. ASQ Quality Press.

Narasimhan, R. \& Kim, S.W. (2002). Effect of supply chain integration on the relationship between diversification and performance: Evidence from Japanese and Korean firms. Journal of Operations Management. 20, 303-323. 
Noble, C. H., Sinha, R. K. \& Kumar, A. (2002). Market orientation and alternative strategic orientations: A longitudinal assessment of performance implications. Journal of Marketing. 66(3), 25-39.

O’Leary-Kelly, S.W. \& Flores, B.E. (2002). The integration of manufacturing and marketing/sales decisions: Impact on organizational performance. Journal of Operations Management. 20(3), 221-240.

Palomero, S. \& R. Chalmeta. 2014. A guide for supply chain integration in SMEs. Production Planning and Control. 25(5), 372-400.

Pan, Y., Sheng, S. \& Xie, F.T. (2012), Antecedents of customer loyalty: an empirical synthesis and reexamination. Journal of Retailing and Consumer Services. 19(1), 150-158.

Rafiq, M., Fulford, H. \& Lu, X. (2013). Building customer loyalty in online retailing: The role of relationship quality. Journal of Marketing Management. 29(3), 494-517.

Ragatz, G.L., Handfield, R.B. \& Peterson, K.J., (2002). Benefits associated with supplierintegration into new product development under conditions of technology uncertainty. Journal of Business Research. $55(5), 389-400$

Rodrigues, A.M., Stank, T.P. \& Lynch, D.F. (2004). Linking strategy, structure, process and performance in integrated logistics. Journal of Business Logistics. 25(2), 65-94.

Stonebraker, P.W. \& Liao, J. (2004). Environmental turbulence, strategic orientation modeling supply chain integration. International Journal of Operations and Production Management. 24(9), 1037-1048

Swink, M., Narasimhan, R. \& Wang, C. (2007), "Managing beyond the factory walls: effects of four types of strategic integration on manufacturing plant performance". Journal of Operations Management. 25(1), 148-164.

Swink, M., Narasimhan, R. \& Wang, C. (2006). Managing beyond the factory walls: effects of four types of strategic integration on manufacturing plant performance. Journal of Operations Management. 25(1):148-164.

Tsai, K.H. \& Hsui T.T. (2014). Cross-Functional collaboration, competitive intensity, knowledge integration mechanisms, and new product performance: A mediated moderation model. Industrial Marketing Management. 43(2014), 293-303

Waters, D. (2003). Logistics: An Introduction to Supply Chain Management. (1th Press). New York: Palgrave Macmillan.

Wong, C.Y., Boon-ittb, S. \& Wong, C.W.Y. (2011). “The contingency effects of environmental uncertainty on the relationship between supply chain integration and operational performance." Journal of Operations Management. 29, 604-615.

Yeung, J. H. Y., W. Selen, M. Zhang, \& B. Huo. 2009. The effects of trust and coercive power on supplier integration. International Journal of Production Economics. 120(1), 66-78.

Zhao, L., B. Huo, L. Sun \& X. Zhao. (2013). The impact of supply chain risk on supply chain integration and company performance: A global investigation. Supply Chain Management: An International Journal. $18(2), 115-131$.

Zhang, M. \& Hartley, J. (2018). Does guanxi influence product performance and customer loyalty? Journal of Asia Business Studies. 12(3), 233-252. 